\title{
El proceso administrativo en la Ley del Suelo
}

SUMARIO: 1. Introducción: 1. La Ley del suelo.-2. La Ley del suelo y la vigente Ley de lo contencioso-administrativo.-3. La Ley del suelo y la futura Ley de la jurisdicción contencioso-administrativa.-4. Especialidades sobre el proceso administrativo en la Ley del suelo.

1I. Los sujetos del proceso: 1. El órgano jurisdiccional: la competencia.-2. Las partes: la legitimación activa; la acción popular.

III. El objeto del proceso: 1. Actos impugnables.-2. Pretensiones deducibles.

IV. Nacimiento, desarrollo y terminación del proceso. Suspensión del acuerdo impugnado.

V. Efectos del proceso. Ejecución de sentencias.

\section{INTRODUCCIÓN}

1. En el Boletín Oficial del Estado de 14 de mayo de 1956 se ha publicado la Ley de 12 de mayo del mismo año sobre régimen del suelo y ordenación urbana, cuyo capítulo cuarto del Título séptimo, dedicado a regular las «acciones y recursos jurisdiccionales», contiene varios preceptos sobre proceso administrativo. Es más, en principio, según el artículo 222, «tendrán carácter jurídico-administrativo todas las cuestiones que se suscitaren con ocasión o como consecuencia de los actos y convenios regulados en la Ley entre la Comisión de Urbanismo o las Corporaciones locales y los propietarios, individuales o asociados, o Empresas urbanizadoras, incluso las relativas a cesiones de terrenos para urbanizars. Por lo que, en la inmensa mayoría de los casos, los litigios que se susciten con 
arreglo a los preceptos de aquella Ley deberán ser conocidos y resueltos por la jurisdicción contencioso-administrativa, a través de un proceso administrativo.

2. Ahora bien, la Ley sobre régimen del suelo no se contenta con establecer el carácter jurídico-administrativo de las cuestiones suscitadas con ocasión y como consecuencia de los actos regulados en la misma, remitiéndose en lo demás a las normas comunes sobre el proceso administrativo, sino que, siguiendo el criterio de otras disposiciones sobre Derecho material, contiene normas de carácter procesal (1). Sin duda, por creer sus redactores que la regulación vigente sobre el proceso administrativo ofrecía graves inconvenientes, trataron, en la medida que les fué posible, modificar aquella regulación, al menos en lo que afectara a las cuestiones suscitadas con ocasión de la nueva Ley del suelo. De este modo nos encontramos con una serie de disposiciones sobre el acontenciosoadministrativon, que han modificado el régimen ordinario contenido, fundamentalmente, en el Texto refundido de la Ley de lo contencioso-administrativo aprobado por Decreto de 8 de febrero de 1952 (2). Es decir, cuando se trata de un arecurso contencioso-administrativon fundado en las disposiciones de la Ley del suelo (según el art. 222), su régimen jurídico vendrá dado por lo dispuesto en los artículos 222 a 228 de aquella Ley y en lo no previsto en ellos por lo que disponen las disposiciones generales sobre el contencioso-administrativo. De aquí la importancia de examinar hasta qué punto la nueva Ley del suelo ha supuesto una modificación del régimen jurídico ordinario de nuestro acontencioso-administrativon.

3. Pero existe otro aspecto de la cuestión todavía más impor-

(1) Sobre la conveniencia o no de seguir tal criterio, me remito a mi trabajo El recurso contencioso-administrativo y el Texto refundido de la Ley de Régimen Local, en "Revista de Estudios de la Vida Local", núm. 84 (1955), págs. 847 y ss., y El Texto refundido de la Ley de lo Contenciosoadministrativo, en "Revista de Administración Pública", núm. 7, págs. 193 y siguientes.

(2) Cfr. obs. cits. en nota anterior y bibliografía que allí se cita, y La sentencia administrativa. Madrid, 1954, págs. 39 y ss. 
tante. La repercusión en la reciente Ley del suelo de los preceptos contenidos en la Ley de la jurisdiccion contencioso-administrativa, cuyo proyecto ha sido enviado recientemente a las Cortes por el Gobierno. Caso de que el proyecto obtenga la sanción legislativa, ¿implicará la derogación de los preceptos sobre contenciosoadministrativo contenidos en la vigente Ley del suelo? Vale la pena meditar sobre el problema, en líneas generales, a fin de que, a ser posible, en el texto definitivo de la Ley de la jurisdicción contenciosoadministrativa se supere toda duda interpretativa sobre la dualidad de textos. Pues bien, en nuestra opinión, el problema hay que plantearlo desde dos puntos de vista: conveniencia o no de la derogación de los preceptos de la Ley del suelo y, caso de que se opte por una u otra solución, forma de que la misma no ofrezca dudas interpretativas.

a) En orden al primer aspecto, es indudable que el proyecto de Ley de la jurisdicción contencioso-administrativa ha adoptado como principio fundamental el de la unidad legislativa. Cree esencial que un solo texto debe contener todas las disposiciones vigentes sobre la jurisdicción contencioso-administrativa y sobre los procesos que se tramitan ante la misma. Estima que el administrado o la entidad que tiene que acudir a los Tribunales administrativos en defensa de sus derechos e intereses jurídico-administrativos no debe tener que acudir a más de un texto legal para conocer la regulación del proceso en que su pretensión ha de ser examinada. Así lo demuestra la cláusula derogatoria del proyecto, al decir que aquedan derogadas todas las disposiciones legales y reglamentarias relativas a la jurisdicción y procedimiento contencioso-administrativos, y las reguladoras del procedimiento administrativo, en cuanto se opongan a la presente Leyo. Es decir, el texto deroga : respecto de la regulación de la jurisdicción y procedimiento contencioso-administrativos, todas las disposiciones; respecto del procedimiento administrativo, las disposiciones que se opongan a la Ley. En una palabra, mientras que respecto del proceso administrativo contiene una disposición expresa-deroga todas las disposiciones vigentes-, respecto al procedimiento administrativo contiene la fórmula general de derogar unicamente la disposiciones que se opongan a los preceptos de la nueva Ley. El proyecto, por tanto, tiende a la máxima 
unidad en la regulación del proceso administrativo, de análoga manera a como también lo pretendió el anteproyecto de Ley de expropiación forzosa, que luego, debido a la oposición de varios sectores $y$, sobre todo, a la tendencia de ciertos Departamentos a conservar su normativa propia, pese a carecer la especialidad de la más lógica fundamentación, al convetirse en ley dejó fuera de su ámbito aspectos fundamentales del procedimiento expropiatorio (3). Esperemos que en el presente caso no ocurra así y que las Cortes sepan respetar y comprender el que ha sido postulado esencial de! Gobierno en la redacción del proyecto: la unidad.

b) Después de lo dicho, fácilmente se comprende que, de no contener el texto de la Ley de la jurisảicción contencioso-administrativa salvedad 2'guna respecto de los preceptos sobre proceso administrativo de la Ley del suelo, la entrada en vigor de aquélla implicará la derogación de éstos, a excepción del artículo 222, que se limita a atribuir a la jurisdicción contencioso-administrativa el conocimiento de ciertas cuestiones, en armonía con lo dispuesto en el artículo $\left.3 .^{\circ}, c\right)$ del proyecto, al menos en cuanto pueda entenderse que ciertas cuestiones derivadas de la Ley del suelo no pueden considerarse propiamente administrativas. Pues es evidente que si fue. se una cláusula derogatoria general-derogar lo que se oponga a la nueva Ley-podría entenderse que subsisten vigentes los

(3) Como he dicho en otra ocasión, pese a la aspiración inicial de superar la profusión de normas sobre la materia que movió al Ministerio de Justicia y a la Comisión redactora del Anteproyecto, la resistencia opuesta por ciertos departamentos malogró aquella laudable aspiración de recoger en un texto único - texto único legal y texto unico reglamentario- las normas vigentes sobre expropiación forzosa, $v$ surgió la necesidad de que en la tercera de las disposiciones finales de la Ley se autorizara al Gobierno "para que a propuesta de una Comisión designada por el Ministro de Justicia, determine mediante Decreto cuáles son las disposiciones vigentes sobre expropiacion forzosa que habrán de continuar en vigor". Cfr. GonzÁlez PÉREZ: La utılidad pública y el interés social en la nueva Ley de Expropiación forzosa, en "Revista Crítica de Derecho Inmobiliario", mayo-junio 1955, pág. 278.

En la línea crítica de la tendencia se logró la consagración definitiva en el texto legal, vid. también GARcia DE ENTERRfa: Los principios de la nueva Ley de Expropiación forzosa. Instituto de Estudios Políticos. Madrid, 1956, págs. 32 y ss. 
preceptos de la Ley del suelo, en aplicación del principio de que ley general posterior no deroga ley especial anterior. Pero como el texto del proyecto deroga expresamente todas las disposiciones sobre la jurisdicción y procedimiento contencioso-administrativoś, la derogación de los preceptos de la Ley del suelo sobre la materia está fuera de duda.

c) Ahora bien, ¿conviene tal derogación? Realmente, como después veremos, si los preceptos sobre acontencioso-administrativon de la Ley del suelo contienen ciertas innovaciones respecto de la arcaica-aunque recientemente refundida-normativa vigente, apenas si son de importancia respecto de la nueva Ley de la jurisdicción contencioso-administrativa, si es que las Cortes respetan el progresivo y generoso criterio del Gobierno, plasmado en el proyecto. Por el contrario, creemos que con la nueva Ley de la jurisdicción contencioso-administrativa el administrativo tiene garantizados más que suficientemente su esfera jurídica $\dot{y}$. el respeto a la legalidad en todos los aspectos, incluso en materia de régimen del suelo. De aquí que sea discutible la conveniencia de mantener la vigencia de unos preceptos muy específicos. Sin embargo, es probable que valga la pena mantener algunas especialidades, pero no en la Ley del suelo, sino recogiéndolas en el proyecto de Ley de la jurisdicción contencioso-administrativa.

4. Esto supuesto, vamos a examinar cuáles son estas especialidades sobre el proceso administrativo contenidas en la Ley del suelo, siguiendo la sistemática comúnmente admitida en el estudio ciel mismo.

\section{LOS SUJETOS DEL PROCESO}

1. El órgano jurisdiccional.-De los distintos aspectos que ofrece el régimen jurídico del órgano jurisdiccional, la reciente Ley del suelo contiene preceptos que se refieren especialmente a uno de ellos : la competencia. Resulta indudable que, en buena parte, tales preceptos resultarán afectados por la futura regulación del proceso administrativo, al sustituir los actuales Tribunales provinciales de lo contencioso-administrativo por Salas de lo contencioso-administrativo en las Audiencias territoriales, a las que se trasladará 
la competencia que hoy corresponde a aquéllos. Pero, en otros aspectos, los preceptos sobre competencia contenidos en la Ley del suelo no están en contradicción con la futura regulación del proceso administrativo. Veamos cuáles son las normas sobre competencia de la Ley de 12 "de mayo de 1956 :

a) Según el artículo 225, 1, de la Ley del Suelo, alos actos de aprobación definitiva de Planes de ordenación y proyectos de urbanición serán recurribles ante el Tribunal provincial contencioso-administrativo con jurisdicción en el territorio del planeamiento, y si afectare a más de una provincia, ante el Tribunal Supremon.

b) Según el artículo 226, los actos de reparcelación ase podrán impugıar, en cuanto causaren estado, ante los Tribunales provinciales de lo contencioso administrativon.

2. Las partes.-De los distintos aspectos que ofrece el régimen jurídico de las partes, ofrece especial atención .el de la legitimación, al que dedica un importante precepto la Ley del suelo: el artículo 223. Sabido es que entre las pretensiones que pueden deducirse ante la jurisdicción contencioso-administrativa se incluyen las de anulación. En ellas, el demandante solicita del Tribunal, no el reconocimiento de una situación jurídica individualizada, sino, meramente, la anulación del acto o de la disposición dictada por la Administración pública. En orden a en qué casos está legitimado el demandante para deducir la pretensión ( $y$, en consecuencia, puede el Tribunal examinarla en cuanto al fondo), pueden, en principio, seguirse tres sistemas (4):

a) Que únicamente puede solicitar la anulación el que ostente un derecho subjetivo que pueda resultar lesionado por el acto o disposición en razón a los cuales se formula la pretensión. Con arreglo a los cánones clásicos del Derecho francés, con su rígida separación entre anulación y plena jurisdicción, en un principio, en aplicación de la llamada uexcepción de recurso paralelos, no podía solicitar la anulación de un acto aquel que, siendo titular de un

(4) Sobre el problema general de la legitimación activa, me remito a mi trabajo La legitimacion activa en el proceso administrațivo, en "Revista de Derecho Procesal", 2. "época, núm. 2. 
derecho subjetivo lesionado, podía acudir a un contencioso de plena jurisdicción. Pero en España, la posibilidad de que el titular de un derecho subjetivo se limite a solicitar la anulación resulta indiscutible. Es más, cuando la vieja Ley de lo contencioso, en su artícuio $1 .^{\circ}$, exigía para poder interponer un arecurso contencioso-administrativon la lesión de un derecho administrativo, lo que en realidad establecía era un requisito de legitimación, pero tal artículo no impedía al titular de un derecho solicitar funicamente la anulación. Lo ha reconocido expresamente la jurisprudencia. Por ejemplo, una sentencia de 11 de mayo de 1950, de la que fué ponente el inolvidable D. Pío Ballesteros, en su tercer considerando, afirmó : aque en el presente pleito se solicita dejar sin efecto la Orden ministerial recurrida, y por cuanto no se insta declaración sustitutiva alguna, patentizáse así que se viene a ejêrrcer en méritos de derechos subjetivos un recurso objetivo, de perfecto acuerdo con lo que para resoluciones de la Administración central viene autorizando constantemente la jurisprudencia de este Tribunalp.

b) Reconocer tal posibilidad al que ostenta un interés en la anulación, con más o menos amplitud. Y se habla de interés personal, directo, legítimo, actual, etc. Ha sido el tradicional sistema francés, si bien una jurisprudencia progresiva ha ampliado de tal modo los casos en que se está legitimado para deducir un arecurso por exceso de padero, que lo difícil es precisar en qué casos no se tiene, realmente, el ivterés exigido para recurrir (5). No obstante, en casi todos los países que siguen las inspiraciones del Derecho francés - las más de las veces adoptando principios y reglas que el propio Derecho francés ha superado-, siguen hablando de los requisitos exigidos al interés para iegitimar al demandante en un acontencioso de anulación» (6).

(5) Cfr. GonzÁlez Pérez: Derecho procesal administrativo. Madrid, 1955, I, págs. 318 y ss.

(6) Cfr., por ejemplo, en lengua española, Bielsa: Sobre lo contenciosoadministrativo, 2.8 ed., Buenos Aires, 1954, págs. 140 y ss.; Sayagués: El Tribunal de lo Contencioso-administrativo. Montevideo, 1952, págs. 91 y ss.; Dana: El nuevo Codigo de lo Contencioso-administrativo de Santa Fe, 1951, 
c) Y cabe, por último, 'a más amplia fórmula : ia acción popular. aEn la acción popular - dice Bielsa-, el grado de interés no se ca:ifica o dosifica. Es un ciudadano (salvo casos especiaies en que no cabe requerirse esta calidad) el que impugna un acto lesivo para el interés general, porque ese acto viola la ley, o perjudica el patrimonio de un ente público, o implica una inmoralidad, o restringe arbitrariamente la libertadø. aEl actor popular no necesita invocar la lesión de un derecho subjetivo ni de un interés legítimo, aunque para él esa lesión exista. Le basta invocar su cualidad de ciudadano sin interdicciones, para asumir la defensa de la legalidado (7).

Pues bien, la Ley del suelo, en su artículo 223 crea una verdadera acción popular (8), al decir que aserá pública la acción para exigir ante los Tribunales contencioso-administrativos la observancia de la presente Ley y de los Planes de ordenación urbanan. Realmente, si pensamos en la trascendencia de la nueva legislación, en los instrumentos que la misma pone en manos del Poder público, en los importantes intereses afectados, no parece arriesgado concluir en la conveniencia de mantener el carácter público de la acción. Porque si para que realmente pueda hablarse de justicia en las relaciones administrativas resulta imprescindible el equilibrio entre la prerrogativa y la garantía, el sometimiento de la Administración a la ley en materia de ordenación urbana sólo podrá lograrse plenamente con un contencioso eficaz, al que puedan acudir los particulares con la máxima amplịtud.

Ahora bien, la conservación del precepto de la Ley del suelo no quiere decir que se mantenga el artículo 223 de la misma, sino que

págs. 56 y ss.; Alvarez TaBio: El proceso contencioso-administrativo. La Habana, 1954, págs. 49 y ss., etc.

Sin embargo, en algunos países se adopta una formula amplia. Cfr., por ejemplo, Dfaz: La jurisdicción contencioso-administrativa en Panamá. Panamá, 1947, pág. 25.

(7) BIELSA: La accíon popular y la facultad discrecional administrativa, en "La Ley", núm. 11.723, t. 73. Secc. doctrina, pág. 713.

(8) Cfr. el completo estudio de Fernández DE VELASCo: La acción papular en el Derecho administrativo. Madrid, 1920. 
debe ser recogido en la futura Ley de la jurisdicción contencioso. administrativa en el precepto correspondiente a la legitimación activa.

\section{EL OBJETO DEL PROCESO}

1. Actos impugnables.-Resulta interesante examinar el catálogo de actos susceptibles de impugnación ante la jurisdicción administrativa con arreglo a la Ley del suelo.

a) En principio, con arreglo a la nueva Ley, son susceptibles de impugnación ante la jurisdicción contencioso-administrativa todos los actos de la Administración dictados en la materia. Lo pone de manifiesto el artículo 225 de la Ley del suelo, al decir que cabe recurso contencioso en relación a : «los actos de aprobación definitiva de Planes de ordenación y proyectos de urbanización», y alos demás acuerdos de las Corporaciones locales, Comisiones y Consejo Nacional de Urbanismo y Ministerio de la Gobernación». Naturalmente, únicamente será admisible el recurso contencioso cuando el acto haya "causado estadon. Para lo que habrá que acudir, en cada caso, a la reglamentación contenida $\in \mathrm{n}$ la Ley del suelo. Pero estas normas no necesitan de aclaración específica. A la luz de la futura Ley de la jurisdicción contencioso-administrativa es posible llegar a la misma conclusión, sin necesidad de mantener tan específica disposición.

b) Ahora bien, aquel principio general contiene algunas excepciones. La Ley del suelo exime de la posibilidad de recurso contencioso-administrativo a ciertos actos. En unos casos, en absoluto. En otros, respecto de ciertas pretensiones. Veamos cuáles son unos $\mathrm{y}$ otros.

$\left.1 .^{\circ}\right)$ No es posible deducir arecurso contencioso-administrativon respecto de aquellos actos aen que la presente Ley no admitiere recurso algunon. Así lo dice el artículo 225, 2, de la Ley del suelo. ¿Es realmente necesaria tal disposición ? En principio, sí. Pues como quiera que existe reiterada jurisprudencia de nuestro Tribunal Supremo, dictada en aplicación del número $6 .^{\circ}$ del artículo $4 .^{\circ}$ de la Ley de lo contencioso (texto refundido), según la cual cuando una ley señala que no cabe contra un acto recurso alguno, ha de entenderse que se refiere a la vía administrativa, pues para excluir de im- 
pugnación cortenciosa, hace falta que jo sea expresamente, resuita indudable que ei mantenimiento de los preceptos cie ia Ley del suelo que afirman la improcedencia de recurso alguno, no implicaría la imposibilidad del acontencioso-administrativos sin el precepto que se contiene en el artículo 225, párrafo 2, de la Ley del suelo.

2. ) No es posible deducir una pretensión de anulación respecto de los aactos de reparcelaciónı, según el artículo 226. Ahora bien, no se trata en estos casos de una exclusión total del contencioso respecto de los mismos, pues aun cuando no es posible solicitar su anulación, ase podrán impugnar, en cuanto causen estado, ante los Tribunales... con objeto de que declaren si existe lesión en más del sexto para el recurrente, y si procediere la responsabilidad civil de la Corporación $\mathbf{u}$ organismos que los hubieren aprobado y, en su caso, también la del funcionario correspondienten.

2. Pretensiones de las partes.-Respecto de los actos susceptibles de impugnación, el particular podrá deducir las pretensiones que, según el derecho material que sirvan de fundamento a las mismas, estime procedente. Salvo la limitación señalada en el artículo 226, que sólo permite deducir una pretensión de indemnización respecto de los a actos de reparcelación , en los demás casos no existe una limitación general. En principio cabe cualquier tipo de pretensión : de anulación, de reconocimiento de una situación jurídica individualizada. Dependerá del derecho material que fundamente la pretensión y de lo que el demandante estime oportuno.

\section{NACIMIENTO, DESARROLLO Y TERMINACIÓN DEL PROCESO}

En orden al nacimiento, desarrollo y terminación del proceso, la Ley del suelo no contiene modificaciones importantes. Las pretensiones deducidas en relación con los actos dictados en aplicación de dicha Ley y fundadas en sus preceptos, serán examinadas y actuadas, en su caso, a través de los trámites normales del proceso administrativo. El procedimiento no sufre variación sustancial. Ahora bien, como con arreglo a la legislación actual existe la distinción entre dos tipos de proceso administrativo, según que el acto en razón al cual se formule el arecurso contencioson proceda de un órgano del Estado o de una Ėntidad local, la Ley del suelo señala en qué casos se aplicará el ré- 
gimen de uno u otro proceso. El párrafo 3 del artículo 225 dice que ala impugnación de los actos de las Comisiones provinciales será admisible bajo las mismas modalidades que los de las Corporaciones localess. Por lo que en los demás casos, según se trate de una Corporación local o de un órgano estatal, se seguirá el régimen del proceso correspondiente. Essta dịstinción carecerá de importancia si adquiere la sanción legislativa el proyecto de Ley de la jurisdicción contencioso-administrativa actualmente en las Cortes.

Ahora bien, si existe una disposición específica en la Ley del suelo que se refiere al nacimiento del proceso. Concretamente, a los efectos de la iniciación del proceso, mediante la presentación del correspondiente escrito de impugnación. El artículo 227 contiene normas sobre la suspensión de obras de urbanización, al decir : al. Si en virtud del ejercicio de acciones... contra actos de la Administración se solicitare por alguna de las partes la suspensión de obras de urbanización, el Tribunal que conozca de la reclamación deducirá testimonio suficiente y lo comunicará a la Comisión Provincial de Urbanismo para que, considerando si las obras responden a un Plan y las conveniencias del interés general, acuerde o no la suspensión en plazo de quince días. 2. El Tribunal que conociera de la reclamación exigirá a la parte que obtuviere la suspensión o a la que ejecutare las obras, si por motivo de interés general no se suspendieren, caución suficiente para cubrir los daños y perjuicios que con la suspensión - la ejecución pudieran irrogarsed.

Sí parece aconsejable mantener esta disposición específica, exigida por la naturaleza de las cuestiones que se planteen con arreglo a lo dispuesto en la reciente Ley sobre régimen del suelo y ordenación urbana.

\section{EFECTOS DEL PROCESO}

Tampoco en orden a los efectos del proceso se contienen normas específicas. Unicamente se regula especialmente los efectos ejecutivos. A la ejecución de la sentencia se refiere el artículo 228 de la Lrey del suelo. En sus párrafos 1 y 2 se contiene la siguiente regulación : a1. Si en virtud de sentencia se hubiere de desistir de la construcción o destruir alguna obra de urbanización, el Juzgado o 
Triburai al que compete ejecutar el fallo lo comunicará a ia Comisión Provincial de Urbanismo para que en el plazo de dos meses notifique al órgano jurisdiccional si, por motivos de interés público, se impone seguir o conservar la obra, y si no lo hiciere, se entenderá que nada obsta a la ejecuciónı. En este precepto no se contiene especialidad alguna importante. La Ley del suelo se limita a aplicar a los supuestos concretos por ella regulados lo que se dispone en el artículo 92 del Texto refundido de la Ley de lo contencioso, sin otra salvedad que establecer una nueva causa de inejecución o suspensión (justificada indudablemente), así como delimitar el órgano que tiene que decidir acerca de ella (en vez del Gobierno, es la Comisión Provincial de Urbanismo).

$Y$ en el párrafo 2 de dịcho artícuio se añade: aSi dispusiere la prosecución o conservación de la obra, el Juzgado o Tribunal fijará la indemnización que el condenado deba abonar al perjudicado, en la forma dispuesta en los artículos... 92 de la Ley de lo contencioso-administrativod. No se trata, por tanto, de ninguna norma especial.

En orden a lo dispuesto en el párrafo 1 de este artículo 228, sí conviene conservar la especialidad en el mismo contemplada, manteniéndose tal causa de inejecución y que sea la Comisión Provincial de Urbanismo la que decida acerca de la misma.

\author{
Jesús González PÉRez \\ Profesor adjunto de Derecho administrativo. \\ Registrador de la Propiedad.
}

